\title{
Preference of spectral features in auditory processing for advertisement calls in the music frogs
}

\author{
Yanzhu Fann ${ }^{1,2 \dagger}$, Xizi Yue ${ }^{1 \dagger}$, Jing Yang ${ }^{1,2}$, Jiangyan Shen ${ }^{1,2}$, Di Shen ${ }^{1,2}$, Yezhong Tang ${ }^{1}$ and Guangzhan Fang ${ }^{1 *}$ (D)
}

\begin{abstract}
Background: Animal vocal signals encode very important information for communication during which the importance of temporal and spectral characteristics of vocalizations is always asymmetrical and species-specific. However, it is still unknown how auditory system represents this asymmetrical and species-specific patterns. In this study, auditory event related potential (ERP) changes were evaluated in the Emei music frog (Babina daunchina) to assess the differences in eliciting neural responses of both temporal and spectral features for the telencephalon, diencephalon and mesencephalon respectively. To do this, an acoustic playback experiment using an oddball paradigm design was conducted, in which an original advertisement call (OC), its spectral feature preserved version (SC) and temporal feature preserved version (TC) were used as deviant stimuli with synthesized white noise as standard stimulus.

Results: The present results show that 1) compared with TC, more similar ERP components were evoked by OC and SC; and 2) the P3a amplitudes in the forebrain evoked by OC were significantly higher in males than in females.

Conclusions: Together, the results provide evidence for suggesting neural processing for conspecific vocalization may prefer to the spectral features in the music frog, prompting speculation that the spectral features may play more important roles in auditory object perception or vocal communication in this species. In addition, the neural processing for auditory perception is sexually dimorphic.
\end{abstract}

Keywords: Auditory processing, Advertisement call, Event related potential (ERP), Spectral characteristic, Temporal characteristic, Frog

\section{Background}

Vocal communication plays a crucial role in the survival and reproduction success in vocal animals such as birds, insects and anurans. In general, animal vocal signals encode diverse information about species, sexual receptivity, location, size and individual identity [1-3]. In the time domain, a natural vocalization typically contains a number of discrete components, appropriately ordered in time, each having specific spectral and temporal characteristics [4]. Accordingly, animal vocalizations provide a rich source of information which receivers must

\footnotetext{
* Correspondence: fanggz@cib.ac.cn

${ }^{\dagger}$ Yanzhu Fan and Xizi Yue contributed equally to this work.

'Department of Herpetology, Chengdu Institute of Biology, Chinese

Academy of Sciences, No.9 Section 4, Renmin Nan Road, Chengdu, Sichuan

610041, People's Republic of China

Full list of author information is available at the end of the article
}

decode for species discrimination and individual recognition [5]. Previous studies show that the relationship between vocal signals and auditory processing is often consistent with the matched filter hypothesis [6], which holds that coevolution of signals and sensory systems should result in a good match between signal structure and the tuning of relevant sensory systems. For example, in zebra finches (Taeniopygia guttata), syllable diversity and male performance parameters such as spectral and temporal consistency rather than long song duration or high (directed) song rates are better predictors of which songs a female will find attractive [7].

The vocalization is both species-specific and individually distinct, and it functions in both territory defense and mate attraction [8]. For vocal animals, biotic noise sources from conspecific and heterospecific individuals are usually the major acoustic interference in many

(c) The Author(s). 2019 Open Access This article is distributed under the terms of the Creative Commons Attribution 4.0 International License (http://creativecommons.org/licenses/by/4.0/), which permits unrestricted use, distribution, and 
habitats $[9,10]$. It is conceivable that, to reduce mutual masking, the signals of different species may be shifted by selection pressure to different frequency bands or spectral characteristics, so that species eventually avoid spectral overlap and hence occupy distinct acoustic niches [11]. Compared with other songbirds, the vocal repertoire of zebra finches includes more harmonic complexes with over 15 frequency components, and that differences in frequency separation and relative amplitude of each component lead to differences in pitch and timbre between individuals [12]. Similarly, the advertisement calls in some anuran species possess various spectral features different from each other among conspecific individuals so that these properties contribute toward individual recognition [13-15]. Thus, the spectral attributes of sounds might play important roles in vocal communication. At the neural level, different frequency components can be represented by activity in different frequency-tuned neural subpopulations or channels, i.e. tonotopic representation of sound [16]. Furthermore, vocalizations usually vary in temporal structure and these temporal properties can also play important roles in vocal communication [17]. Correspondingly, another fundamental aspect of auditory processing is neural synchrony to the temporal structure of sound such as envelope following [18] and frequency following [19] found in the instantaneous firing rate of auditory neurons. Interestingly, frequency resolution and temporal resolution for acoustic signals are inversely related to one another, both at the species and individual level in songbirds [20], implying the spectral and temporal features may contribute differently in vocal communication or perception of auditory object, i.e. the fundamental perceptual unit in hearing [21, 22]. Yet, there is still much that remains unknown about how auditory system represents the differences between these two features.

In anurans, survival and reproductive behaviors depend primarily on a listener's ability to parse acoustic signals that convey species identity and individual information [23]. Usually, males are highly vocal and generally produce species-specific advertisement calls to attract females for breeding, as well as to deter rivals [24-26]. For species discrimination, either temporal information $[5,27]$ or spectral one $[14,28]$ may be more important in many anuran species. For individual recognition, the fundamental frequency and correlated spectral properties in advertisement calls of some species are often the most individually distinct call properties and contribute toward assigning calls to correct individuals [13-15, 29-31]. In contrast, female choices in some species are often mediated by temporal characteristics of calls [5, 32-34]. Interestingly, the temporal and spectral acoustic cues are used for sexual identity recognition and conveying female attractiveness respectively in Xenopus laevis [35]. These results suggest that the significance of temporal and spectral features of vocalizations is asymmetrical and species-specific for vocal communication. Numerous studies suggest that anurans have neural specializations for analyzing the temporal and spectral structures. In addition, anurans typically exhibit a small vocal repertoire and communicate in well-defined behavioral contexts making these species well suited for studies of auditory perception [36, 37]. However, it is still unknown how auditory system represents this asymmetrical and species-specific differences in temporal and spectral features of vocalizations observed in behaviors.

The Emei music frog (Babina daunchina) is a typical seasonal reproductive species in which males produce advertisement calls either from inside underground nest burrows or from outside burrows in the breeding season [38-41]. The resonant properties of the nest burrows modify call acoustics, such as extending note duration and decreasing note fundamental frequency, yielding two types of advertisement calls. Calls produced from inside the nests are highly sexually attractive (HSA) to females while those produced from open fields are of low sexual attractiveness (LSA) [40]. Females prefer HSA calls to LSA calls in phonotaxis experiments and males more likely to compete against HSA calls compared to LSA calls [40, 41], consistent with the idea that selective attention may be involved in anuran auditory perception [42, 43] and males can maximize fitness by adjusting competitive strategies to match female preferences and avoid the interference of other males [44]. These results also indicate differences in the temporal or spectral features of advertisement calls are easily recognized by the music frogs, providing an excellent model system for studying the neural mechanisms underlying auditory object perception of acoustic differences in vocalization. Moreover, compared with the temporal features, spectral properties may provide more sufficient information for individual recognition in this species [38], suggesting the spectral features may play important roles in vocal communication. Electrophysiological studies have shown that HSA and LSA calls can elicit significantly different event-related potential (ERP) components [45-48], suggesting ERP components can depict the differences in neural responses to temporal and spectral features of vocalization. In addition, the music frogs preferentially use the right ear to detect conspecific calls which conveys auditory information most strongly to the left auditory midbrain $[49,50]$, consistent with the idea that discrete brain structures are specialized for different functions [51]. Accordingly, it is logical to hypothesize that specific brain structures will be involved in auditory neural processing in this species. 
ERP is the measured brain response to a specific sensory, cognitive or motor event [52], whose amplitudes and latencies can be used to examine processing efficiency and time course of information processing in the brain. Auditory ERPs generally consist of three main components (N1, P2 and P3) which peak at latencies of $\sim 80 \mathrm{~ms}, \sim 200 \mathrm{~ms}$ and $\sim 300 \mathrm{~ms}$, respectively [53-57]. Functionally, N1 with negative peak is sensitive to selective attention [53]; P2 with positive peak is sensitive to the stimulus complexity and the subject's familiarity with the sound [54]; while P3 can be divided into two general types: P3a elicited by novel deviant stimulus with passive paradigm and P3b (the conventional P3) elicited by the target stimulus with active paradigm [58]. P3a, also known as "novelty P300" [59], is a reflection of automatic detection of a different stimulus or stimulus relative novelty, i.e. novel or more salient differences between standard and deviant stimuli produce larger P3a waves [60]. In addition, familiar sounds evoke smaller P3a compared with unfamiliar ones [61]. Moreover, humanlike auditory ERP components, found in various taxa including non-human primates [62], mammals [63, 64] and anurans [45, 48, 65], may indicate similar brain functions because important neuroanatomical features have been conserved during vertebrate brain evolution [66, 67]. Since discrete brain regions may be specialized for different functions [51], the present study measured the amplitude and latency of each ERP component for the left and right hemispheres in response to three acoustic stimuli (the original advertisement call, OC; and its transformation version with temporal and spectral features preserved respectively, $\mathrm{TC}$ and SC) in order to investigate how auditory central nervous system represents the differences of these two call features in auditory neural processing. Furthermore, the fundamental perceptual unit in hearing is auditory object [21,22], and that its neural representation must be based on information conveyed by one or more senses. Under these conditions we predicted that (1) more similar ERP components would be evoked by OC and $\mathrm{TC}$ if auditory processing of conspecific vocalization prefers to temporal features in the music frog; (2) alternatively, more similar ERP components would be evoked by $\mathrm{OC}$ and SC if the neural processing depends on spectral features primarily; and (3) ERP components will vary across brain structures such as various portions of a brain region.

\section{Materials and methods}

\section{Animals and surgery}

Sixteen adult frogs (8 males and 8 females) were captured from the Emei mountain area of Sichuan, China for the present experiments. Animal husbandry and laboratory animal care were the same as used in previous work and have been described elsewhere [49, 68, 69].
Briefly, the male and female frogs were separated by sex and were breeding in different plastic tanks $\left(45 \times 35 \mathrm{~cm}^{2}\right.$ and $30 \mathrm{~cm}$ deep) which were paved with mud and water and the subjects were fed fresh live crickets every 3 days. The tanks were placed in a constant temperature room $\left(23 \pm 1^{\circ} \mathrm{C}\right)$ that was maintained on a 12:12 light-dark cycle (lights on at 08:00). At the time of surgery, the mean mass and length of the subjects were $11.0 \pm 0.6 \mathrm{~g}$ and $4.6 \pm 0.1 \mathrm{~cm}$ respectively.

The experiments were performed during the reproductive season of this species. Briefly, after anesthetizing the subject using a $0.15 \%$ tricaine methanesulfonate (MS-222) solution [70, 71], 17 cortical electroencephalogram (EEG) recording electrodes, consisting of miniature stainless steel screws $(\phi 0.5 \mathrm{~mm})$, were implanted in the skull. Sixteen electrodes were distributed in the left and right sides of telencephalon (TL1, TR1, TL2, TR2, TL3, TR3), diencephalon (DL4, DR4) and mesencephalon (ML5, MR5, ML6, MR6, ML7, MR7, ML8, MR8), respectively. The reference electrode (C) was placed on the cerebellum (Fig. 1). All electrode leads were formvar-insulated nichrome wires with one end interwined tightly around the screws and the other end tin soldered to the female-pins of an electrical connector. Electrodes were fixed to the skull with dental acrylic. The connector was covered with a self-sealing membrane (Parafilm ${ }^{\circ} \mathrm{M}$; Chicago, USA) that was water-proof and located about $1 \mathrm{~cm}$ above the head of the animal. Finally, the skin edges and muscles surrounding the wound were treated with the ointment with triple antibiotic and pain relief (CVS pharmacy, Woonsocket, RI, USA) to prevent infection and discomfort. Each frog was housed individually for 6 days for recovery before conducting further experiments. After all experiments were completed, the subjects were euthanized by overdose of MS-222 and electrode localizations were confirmed by injecting hematoxylin dye through the skull holes in which the electrodes were installed previously [68].

\section{Recording conditions}

An opaque plastic tank $\left(80 \times 60 \mathrm{~cm}^{2}\right.$ and $\left.60 \mathrm{~cm} \mathrm{deep}\right)$ containing mud and water was placed in a soundproof and electromagnetically shielded chamber (background noise $24.3 \pm 0.7 \mathrm{~dB}$ ). An infrared camera with a motion detector was mounted centrally about one meter above the tank for monitoring the subjects' movement behaviors. Electrophysiological signals were recorded with a signal acquisition system (OmniPlex 64-D, Plexon, USA). And that the sampling rate was set to $1000 \mathrm{~Hz}$.

\section{Stimuli and paradigm}

Time-reversed calls have been used widely in both behavioral and neurophysiological studies because they 


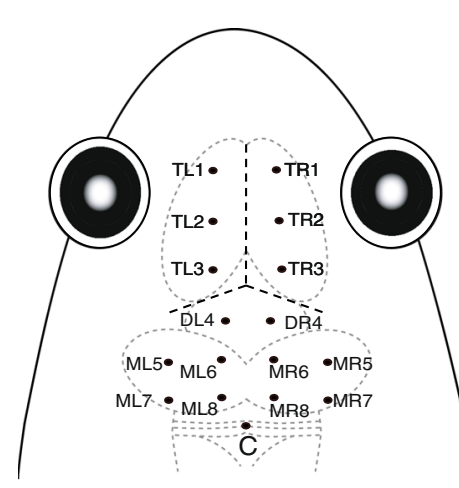

TL1 TR1

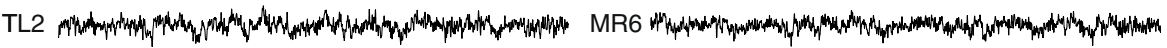
TR2

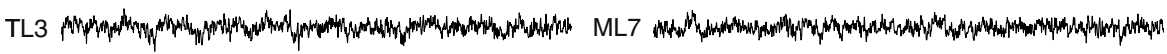

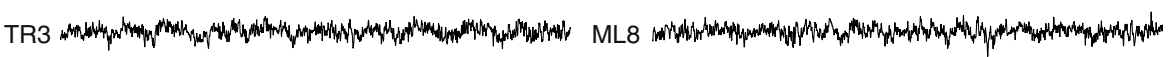
DL4 MR8 DR4

Fig. 1 Electrode placements and their 20 s of typical EEG tracings. The intersection of the three dashed lines in bold in the frog head denotes the intersection of suture lines corresponding to lambda. The electrodes coordinates: TL1 $(-1.5,3.8)$, TR1 $(1.5,3.8)$, TL2 $(-1.5,2.4)$, TR2 (1.5, 2.4), TL3 $(-1.5,1)$, TR3 $(1.5,1)$; DL4 (-0.8, - 0.2), DR4 (0.8, - 0.2); ML5 (-2.2, - 1.6), ML6 $(-0.8,-1.6)$, MR6 $(0.8,-1.6)$, MR5 $(2.2,-1.6)$, ML7 (-2.2, -3.5$),$ ML8 $(-0.8,-3.5)$, MR8 $(0.8,-3.5)$, MR7 $(2.2,-3.5) ; C(0,-4.5)$. Adapted from Yue et al. [46]

contain the same frequencies at the same relative amplitudes as the natural calls although they show frequency modulated (FM) sweeps of reversed order for FM calls [72]. In the present study, four stimuli were used: white noise (WN), a conspecific advertisement call, its reverse version (i.e. each note of the call was reversed so that most spectral attributes of the call was preserved, SC) and its envelope version (i.e. the call envelope filled with white noise so that the most temporal attributes of the call was preserved, TC). The acoustic recording used as playback call was subject to the following criteria: (1) the call contained five notes, which is equal to the mean number of notes in natural male calls and (2) the temporal and frequency parameters of the call were close to the population average. WN without any species-specific temporal-spectral features was constructed and its duration equaled to the duration of the conspecific calls (about $1.2 \mathrm{~s}$ ), shaped with rise and fall time sinusoidal periods of $10 \mathrm{~ms}$ (Fig. 2). Stimuli were played back to subjects via two portable field speakers (SME-AFS, Saul Mineroff Electronics, Elmont, NY, USA) that were placed equidistantly from the opposite ends of the experimental tank. Each stimulus was presented through the two speakers simultaneously at $65 \mathrm{~dB}$ SPL (re $20 \mu \mathrm{Pa}$, C-weighting, fast response; Aihua, AWA6291; Hangzhou, China) measured at the center of the tank, approximately equals to the mean of natural sound pressure level of male calls [38]. Under these conditions, the sound level distribution at the bottom of the bank was close to a quasi-free sound field. Furthermore, subjects usually remained motionless at one corner of the tank throughout the experiments. It is highly unlikely that the tiny differences in the stimulus amplitude across the tank bottom could have a significant effect on the ERP measures.

The oddball paradigm was used in the present study with WN as the standard stimulus and others as the deviant stimuli, in which the probability of presentation for the standard stimulus was $70 \%$ and that for each deviant was $10 \%$. Thus, for each subject a total of 1000 stimulus presentations with each deviant stimulus presented 100 times were broadcasted in a random order within three trial blocks. Randomization was constrained to prevent more than three deviant stimuli from within the same acoustic category being presented successively. A trigger pulse was sent to the signal acquisition system at every stimulus onset through the parallel port for further time-locking analysis. Because the influence of target stimulus probability on P3 amplitude would wane considerably under longer inter-stimulus intervals (ISI) in humans [73], the ISI less than $2 \mathrm{~s}$ was used in most animal studies [45, 64, 74]. In this study, the ISI was set to $1.5 \mathrm{~s}$ although the mean natural inter-call interval of the music frogs is $3.3 \mathrm{~s}$ [41]. Consequently, the session lasted about $50 \mathrm{~min}$ with $5 \mathrm{~min}$ breaks between blocks so that the subjects would not become fatigued [75].

\section{ERP signal collection and measurement}

After postoperative recovery for 6 days, the subject was placed in the experimental tank and connected to the signal acquisition system for about $24 \mathrm{~h}$ habituation. Then the EEG signal and behavioral data were collected according to the above described auditory stimulation paradigm. In order to eliminate the effects of digestion, the subject was not fed during the experimental period. To extract ERP components, EEG recordings were filtered offline using a band-pass filter at $0.25-25 \mathrm{~Hz}$ and a notch filter to eliminate possible interference at $50 \mathrm{~Hz}$ before averaging the stimulus-locked EEG epochs. The EEG signals were divided into epochs with a duration of $700 \mathrm{~ms}$, including a prestimulus baseline of $200 \mathrm{~ms}$. All single EEG trials were inspected visually and trials with muscle artifacts and 


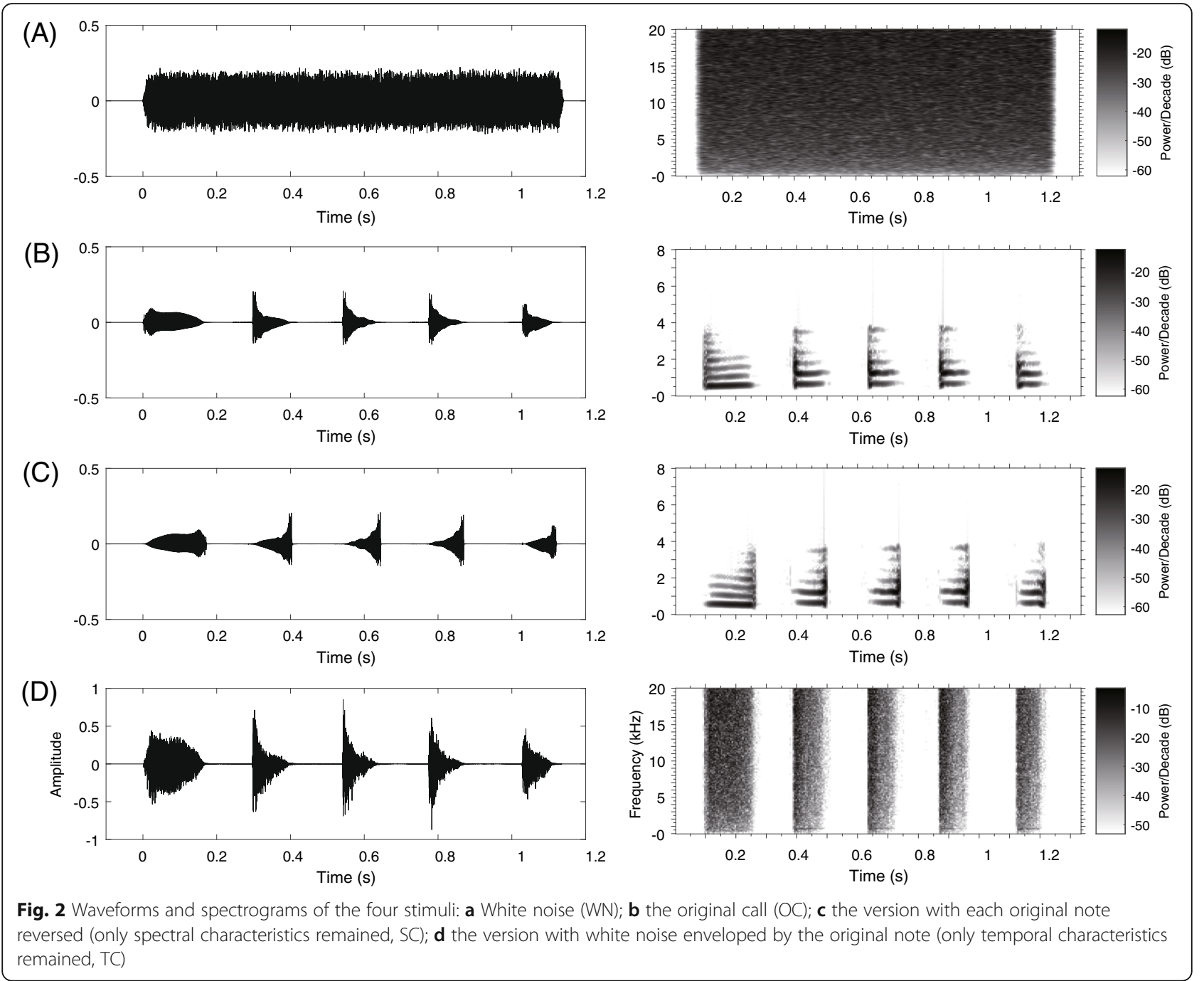

electrode drifts were removed from all further analysis. Accepted trials were averaged according to stimulus types and channels within each session.

For each component, the peak was found in the grand average ERP waveforms for each stimulus and each channel. Then the median was calculated regardless of stimuli and channels, and that the time window with $100 \mathrm{~ms}$ in width was defined with the median as the midpoint. Similar to other studies [45, 76-79], the auditory ERP component N1 was defined as the mean amplitude during latency intervals of $30-130 \mathrm{~ms}$, P2 during intervals of $150-250 \mathrm{~ms}$ and P3a during intervals of 250-350 ms after stimulus onset. The latency was determined by the " 50 percent area latency measure" for each ERP component [52], i.e. measuring the area under the curve within the time windows and finding the time point that divided this area into equal halves. Since difference waveform can be used to compare the relative variation between the ERP responses to the different deviants, they were obtained by subtracting the component amplitude in response to $\mathrm{WN}$ from the amplitude in response to various versions of conspecific calls. Then the amplitude and latency of each ERP component acquired from the difference waveforms (OC-WN, SC-WN and TC-WN) were subjected to further statistical analyses.

\section{Statistical analyses}

The Shapiro-Wilk $W$ test and Levene's test were applied to estimate the normality of the distribution and the homogeneity of variances of the amplitudes and latencies of N1, P2 and P3a, respectively. Since the number of levels of an independent variable has been suggested to be less than eight [80], the amplitudes and latencies of ERP components were statistically analyzed for the telencephalon, diencephalon and mesencephalon respectively. A three-factor repeated measured ANOVA was conducted with the variables of "sex" (male/female), "stimulus" (OC/SC/TC) and "channel" (TL1, TR1, TL2, TR2, TL3 and TR3 for the telencephalon; DL4 and DR4 for the diencephalon; ML5, MR5, ML6, MR6, ML7, 
MR7, ML8 and MR8 for the mesencephalon). Both main effects and interactions were examined; if ANOVAs returned a significant difference, the data would be further tested for multiple comparisons using the least significant difference test. If the interaction was significant, simple effects analysis would be applied. Greenhouse-Geisser epsilon $(\varepsilon)$ values would be employed when the null hypothesis of mauchly's test of sphericity was violated. Effect size was decided by partial $\eta^{2}$ (partial $\eta^{2}=0.20$ is set as a small, 0.50 as a medium and 0.80 as a large effect size, respectively) [81]. SPSS software (release 20.0) was applied for the statistical analysis with the significance level of $p<0.05$.

\section{Results}

The grand average of the original and difference waveforms are shown in Figs. 3 and 4, respectively. There were significant differences among stimuli and sexes but not brain structures in amplitude rather than latency for each ERP component, respectively. Furthermore, SC compared with TC could elicit a more similar response to OC (Table 1).

\section{The amplitude and latency of the $\mathrm{N} 1$ component}

The analysis for the N1 amplitude showed that there was significant main effect for the factor "stimulus" for the telencephalon $\left(\mathrm{F}(2,28)=6.046\right.$, Partial $\eta^{2}=0.302, p=$ 0.007), diencephalon $\left(\mathrm{F}(2,28)=18.626\right.$, Partial $\eta^{2}=0.571$, $p<0.001)$ and mesencephalon $(\mathrm{F}(2,28)=14.442$, partial $\left.\eta^{2}=0.508, p<0.001\right)$, respectively. However, there was no significant main effect for the factors "sex" $(F(1,14)=$ 0.007, Partial $\eta^{2}=0.000, p=0.935$ for the telencephalon; $\mathrm{F}(1,14)=0.219$, Partial $\eta^{2}=0.015, p=0.647$ for the diencephalon; and $\mathrm{F}(1,14)=0.076$, Partial $\eta^{2}=0.005, p=$ 0.787 for the mesencephalon) and "channel" $(F(5,70)=$ $0.720, \varepsilon=0.489$, Partial $\eta^{2}=0.049, p=0.520$ for the telencephalon; $\mathrm{F}(1,14)=1.003$, Partial $\eta^{2}=0.067, p=0.334$ for the diencephalon; and $F(7,98)=0.851, \varepsilon=0.403$,

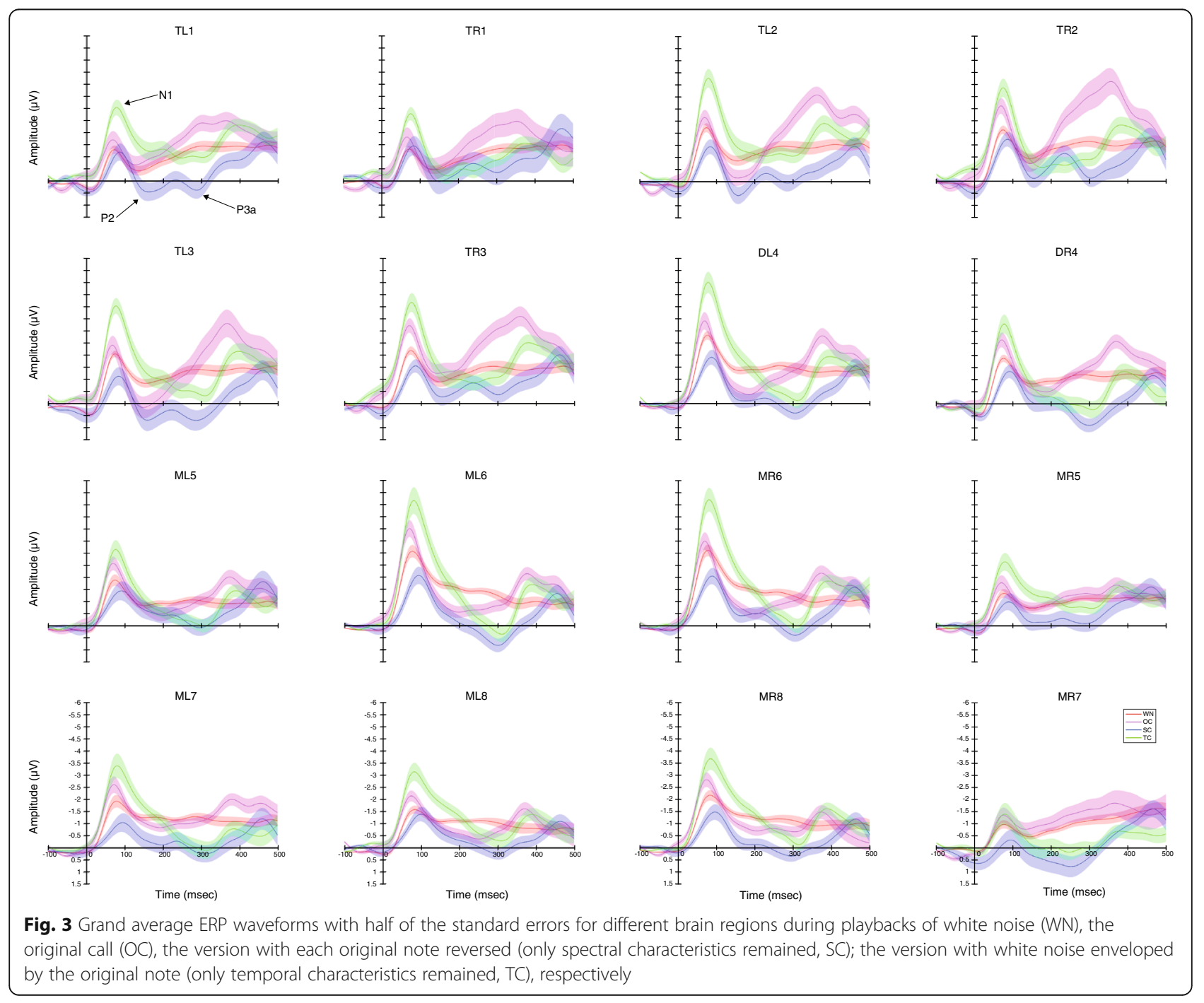




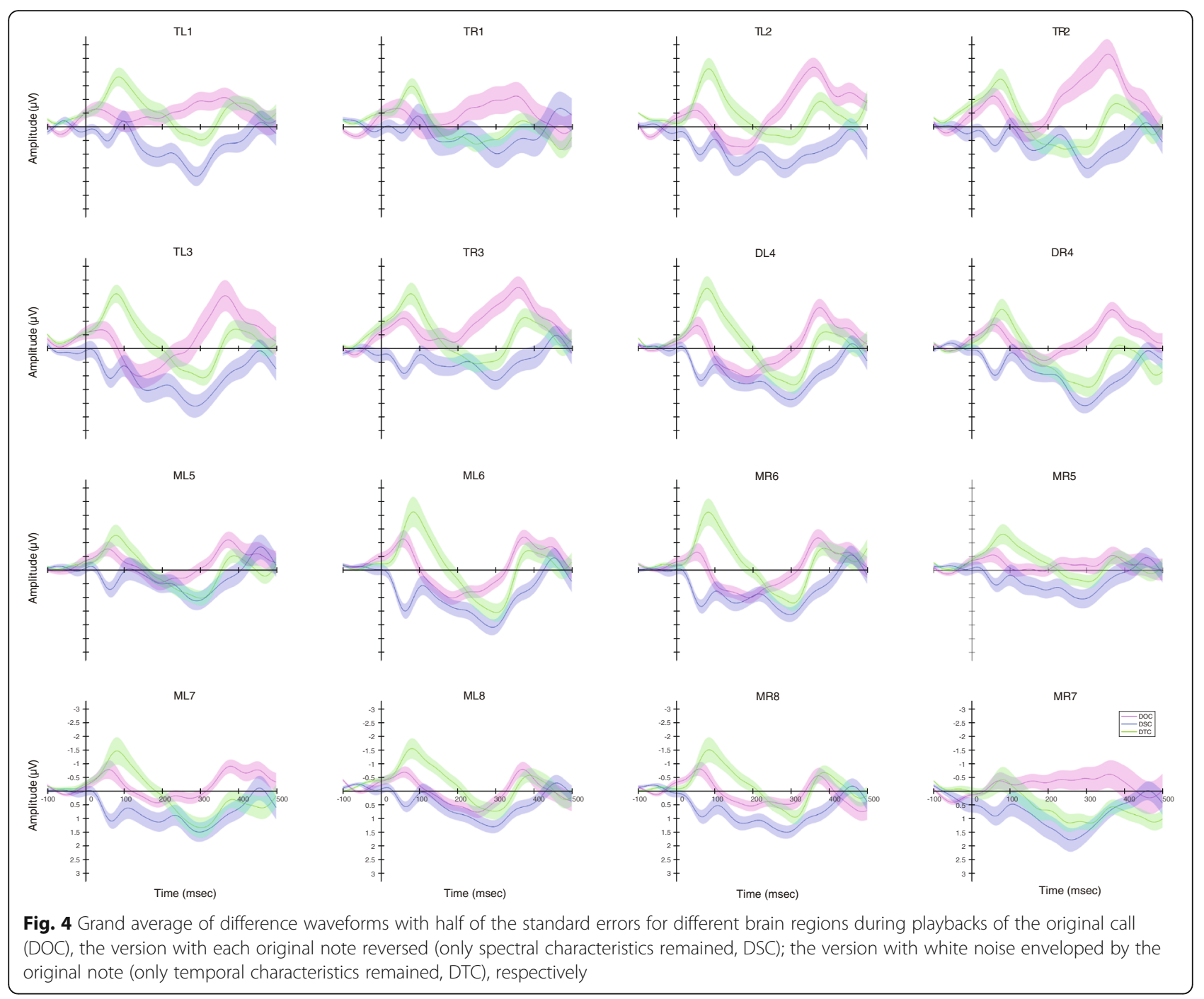

Table 1 The differences between OC and SC or TC (OC-SC and OC-TC) for each ERP component

\begin{tabular}{llll}
\hline ERP component & brain region & OC-SC & OC-TC \\
\hline N1 & Telencephalon & -0.9606 & 1.0952 \\
& Diencephalon & -1.0384 & 1.6570 \\
& Mesencephalon & -1.0701 & 1.1728 \\
P2 & Telencephalon & -0.8183 & 1.0006 \\
& Diencephalon & -0.5074 & 1.5998 \\
P3a & Mesencephalon & -0.5834 & 1.1094 \\
& Telencephalon & -2.5335 & -1.4414 \\
& Diencephalon & -1.9293 & -0.3262 \\
& Mesencephalon & -1.5394 & -0.2660 \\
\hline
\end{tabular}

The raw data was pooled regardless of 'sex' and averaged over different channels because of no significant main effect for the factors 'sex' and 'channel'. Then the difference between $\mathrm{OC}$ and SC (OC-SC) and the difference OC and TC (OC-TC) were calculated for telencephalon, diencephalon and mesencephalon respectively
Partial $\eta^{2}=0.057, p=0.469$ for the mesencephalon). Multiple comparisons showed that the N1 amplitudes evoked by TC were significantly greater than those evoked by $\mathrm{OC}$ and $\mathrm{SC}$ although the difference between $\mathrm{OC}$ and TC did not reach statistical significance for the telencephalon, while the $\mathrm{N} 1$ amplitudes evoked by $\mathrm{OC}$ was significantly higher than that by $\mathrm{SC}$ for the diencephalon and mesencephalon $(p<0.05$; Fig. 5 and Table 2). In addition, for N1 latency there was no significant main effect or interaction for any factor.

\section{The amplitude and latency of the P2 component}

For the P2 amplitude, there was significant main effect for the factor "stimulus" for the telencephalon $(F(2,28)$ $=5.064$, partial $\left.\eta^{2}=0.266, p=0.013\right)$, diencephalon $(\mathrm{F}(2$, 28) $=8.003$, partial $\left.\eta^{2}=0.364, p=0.002\right)$ and mesencephalon $\left(F(2,28)=5.844\right.$, partial $\left.\eta^{2}=0.294, p=0.008\right)$, respectively. However, there was no significant main effect for the factors "sex" $\left(\mathrm{F}(1,14)=0.013\right.$, Partial $\eta^{2}=0.001, p$ 


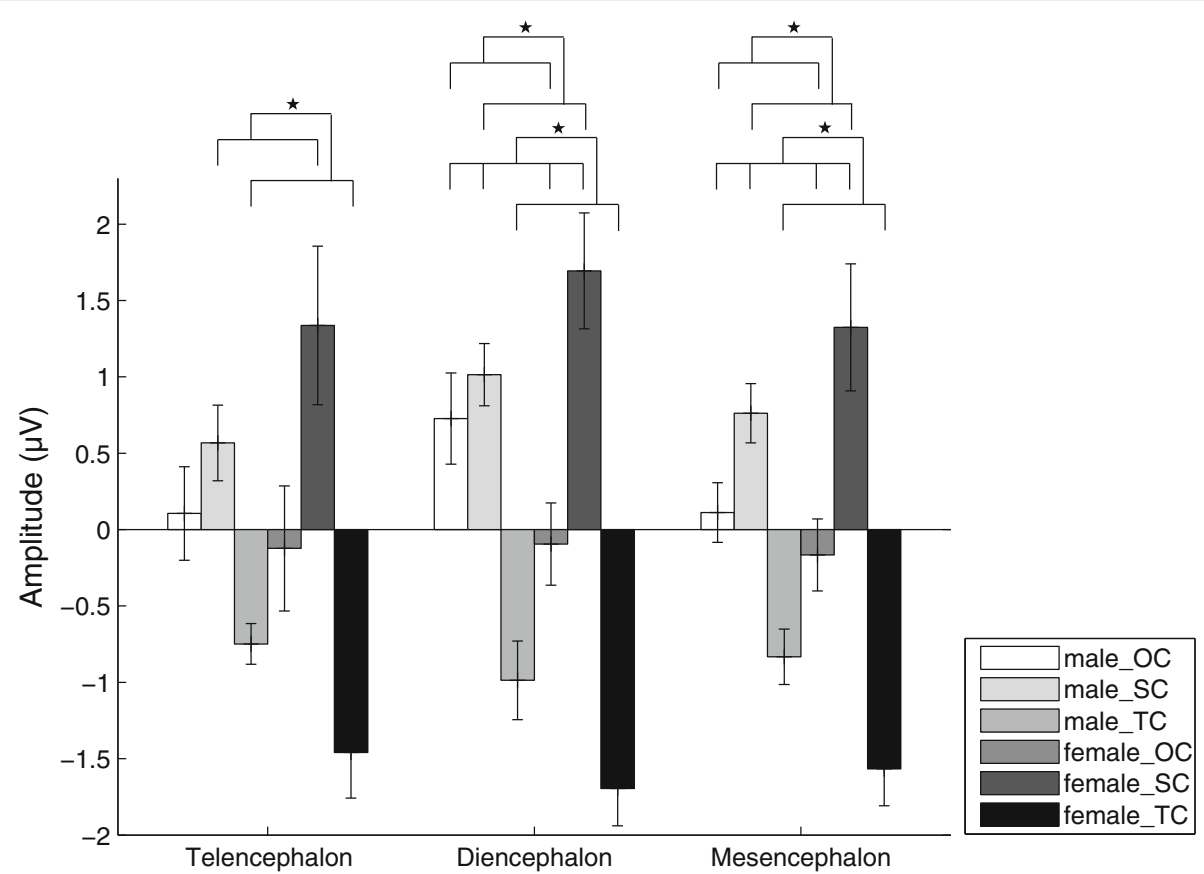

Fig. 5 Means and standard errors for N1 amplitudes during playbacks of the three deviant stimuli for the telencephalon, diencephalon and mesencephalon respectively. OC, the original call; SC, the version with each original note reversed (only spectral characteristics remained); TC, the version with white noise enveloped by the original note (only temporal characteristics remained)

Table 2 Results of ANOVAs for the amplitudes of N1, P2 and P3a with respect to the three factors for the telencephalon, diencephalon and mesencephalon respectively

\begin{tabular}{|c|c|c|c|c|c|c|c|c|c|c|c|c|c|c|c|}
\hline & \multicolumn{5}{|c|}{ for the telencephalon/(2,28),(5,70),(1,14) } & \multicolumn{5}{|c|}{ for the diencephalon/(2,28),(1,14),(1,14) } & \multicolumn{5}{|c|}{ for the mesencephalon/(2,28),(7,98),(1,14) } \\
\hline & $F$ & $\varepsilon$ & $p$ & $\eta^{2}$ & LSD & $F$ & $\varepsilon$ & $p$ & $\eta^{2}$ & LSD & $F$ & $\varepsilon$ & $p$ & $\eta^{2}$ & LSD \\
\hline \multicolumn{16}{|l|}{ N1 } \\
\hline stimulus & 6.046 & NA & $0.007^{*}$ & 0.302 & $\mathrm{TC}>\mathrm{SC}$ & 18.626 & NA & $0.000^{* *}$ & 0.571 & $\mathrm{TC}>\mathrm{OC}>\mathrm{SC}$ & 14.442 & NA & $0.000^{* *}$ & 0.508 & $\mathrm{TC}>\mathrm{OC}>\mathrm{SC}$ \\
\hline channel & 0.720 & 0.489 & 0.520 & 0.049 & NA & 1.003 & NA & 0.334 & 0.067 & NA & 0.851 & 0.403 & 0.469 & 0.057 & NA \\
\hline sex & 0.007 & NA & 0.935 & 0.000 & NA & 0.219 & NA & 0.647 & 0.015 & NA & 0.076 & NA & 0.787 & 0.005 & NA \\
\hline interact & 0.814 & NA & 0.453 & 0.055 & NA & 1.762 & NA & 0.190 & 0.112 & NA & 1.242 & NA & 0.304 & 0.081 & NA \\
\hline \multicolumn{16}{|l|}{$P 2$} \\
\hline stimulus & 5.064 & NA & $0.013^{*}$ & 0.266 & $S C>T C$ & 8.003 & NA & $0.002^{*}$ & 0.364 & $\mathrm{OC}, \mathrm{SC}>\mathrm{TC}$ & 5.844 & NA & $0.008^{*}$ & 0.294 & $\mathrm{OC}, \mathrm{SC}>\mathrm{TC}$ \\
\hline channel & 1.885 & 0.631 & 0.143 & 0.119 & NA & 0.314 & NA & 0.584 & 0.022 & NA & 0.852 & 0.392 & 0.465 & 0.057 & NA \\
\hline sex & 0.013 & NA & 0.910 & 0.001 & NA & 0.374 & NA & 0.551 & 0.026 & NA & 0.128 & NA & 0.726 & 0.009 & NA \\
\hline interact & 3.464 & NA & $0.045^{*}$ & 0.198 & see main text & 2.377 & NA & 0.111 & 0.145 & NA & 1.508 & NA & 0.239 & 0.097 & NA \\
\hline \multicolumn{16}{|l|}{$P 3 a$} \\
\hline stimulus & 6.916 & NA & $0.004^{*}$ & 0.331 & $\mathrm{SC}, \mathrm{TC}>\mathrm{OC}$ & 5.943 & NA & $0.007^{*}$ & 0.298 & $\mathrm{SC}>\mathrm{OC}, \mathrm{TC}$ & 4.365 & NA & $0.022^{*}$ & 0.238 & $\mathrm{SC}>\mathrm{OC}, \mathrm{TC}$ \\
\hline channel & 0.697 & 0.560 & 0.550 & 0.047 & NA & 1.488 & NA & 0.243 & 0.096 & NA & 2.054 & 0.422 & 0.122 & 0.128 & NA \\
\hline sex & 0.822 & NA & 0.380 & 0.055 & NA & 1.178 & NA & 0.296 & 0.078 & NA & 0.258 & NA & 0.619 & 0.018 & NA \\
\hline interact & 6.386 & NA & $0.005^{*}$ & 0.313 & see main text & 3.642 & NA & $0.039^{*}$ & 0.206 & see main text & 1.763 & NA & 0.190 & 0.112 & NA \\
\hline
\end{tabular}

Note: The symbols ' $>$ ' denote that the amplitudes of ERP components evoked by the acoustic stimulus on the left side of ' $>$ ' are significantly larger than those on the right side, and no significant difference exists among the corresponding conditions on the same side of ' $>$ ' for each case. The degrees of freedom are shown after the brain regions for the three factors respectively. Note that only significant interactions are shown. $* p<0.05, * * p<0.001$. Abbreviations: $F$ is the $F$-value from ANOVA; $\varepsilon$, the values of epsilon of Greenhouse-Geisser correction; LSD, least-significant difference test; OC, the original note; SC, the version with each original note reversed (only spectral characteristics remained); TC, the version with white noise enveloped by the original note (only temporal characteristics remained); interact, the interaction between the factors "stimulus" and "sex" 
$=0.910$ for the telencephalon; $\mathrm{F}(1,14)=0.374$, Partial $\eta^{2}$ $=0.026, p=0.551$ for the diencephalon; and $\mathrm{F}(1,14)=$ 0.128 , Partial $\eta^{2}=0.009, p=0.726$ for the mesencephalon) and "channel" $\left(\mathrm{F}(5,70)=1.885, \varepsilon=0.631\right.$, Partial $\eta^{2}$ $=0.119, p=0.143$ for the telencephalon; $\mathrm{F}(1,14)=0.314$, Partial $\eta^{2}=0.022, p=0.584$ for the diencephalon; and $\mathrm{F}(7,98)=0.852, \varepsilon=0.392$, Partial $\eta^{2}=0.057, p=0.465$ for the mesencephalon). And that the interaction between "sex" and "stimulus" was significant $(F(2,28)=3.464$, partial $\left.\eta^{2}=0.198, p=0.045\right)$ for the telencephalon. Simple effects analysis showed that the P2 amplitude evoked by $\mathrm{SC}$ was significantly higher than that by $\mathrm{TC}$ in females ( $p<0.05$; Fig. 6 and Table 2). For the diencephalon and mesencephalon, the P2 amplitudes evoked by OC and SC were significantly higher than that evoked by TC $(p<0.05$; Fig. 6 and Table 2). Similarly, for P2 latency there was no significant main effect or interaction for any factor.

\section{The amplitude and latency of the P3a component}

For the P3a amplitude in the telencephalon, there was significant main effect for the factor "stimulus" $(\mathrm{F}(2,28)$ $=6.916$, partial $\eta^{2}=0.331, p=0.004$ ) but not the factors "sex" $\left(\mathrm{F}(1,14)=0.822\right.$, partial $\left.\eta^{2}=0.055, p=0.380\right)$ and “channel" $\left(\mathrm{F}(5,70)=0.697, \varepsilon=0.560\right.$, partial $\eta^{2}=0.047$, $p=0.550)$. Moreover, the interaction between "sex" and "stimulus" was significant $\left(\mathrm{F}(2,28)=6.386\right.$, partial $\eta^{2}=$ $0.313, p=0.005)$. The P3a amplitudes evoked by SC and $\mathrm{TC}$ were significantly higher than that evoked by $\mathrm{OC}$ in females $(p<0.05$; Fig. 7 and Table 2$)$, and that the P3a amplitude in males evoked by OC was significantly higher than that evoked in females. For the diencephalon, there was significant main effect for the factor "stimulus" $\left(\mathrm{F}(2,28)=5.943\right.$, partial $\left.\eta^{2}=0.298, p=0.007\right)$ but not the factors "sex" $\left(\mathrm{F}(1,14)=1.178\right.$, partial $\eta^{2}=$ $0.078, p=0.296)$ and "channel" $(\mathrm{F}(1,14)=1.488$, partial $\left.\eta^{2}=0.096, p=0.243\right)$. Moreover, the interaction between "sex" and "stimulus" was significant $(\mathrm{F}(2,28)=3.642$, partial $\left.\eta^{2}=0.206, p=0.039\right)$. The P3a amplitude evoked by $\mathrm{SC}$ was significantly higher than those evoked by OC and TC in females ( $p<0.05$; Fig. 7 and Table 2), and that the P3a amplitude in males evoked by OC was significantly higher than that evoked in females. For the mesencephalon, there was significant main effect for the factor "stimulus" $\left(\mathrm{F}(2,28)=4.365\right.$, partial $\eta^{2}=0.238, p=$ $0.022)$ but not the factors "sex" $(\mathrm{F}(1,14)=0.258$, partial $\left.\eta^{2}=0.018, p=0.619\right)$ and "channel" $(\mathrm{F}(7,98)=2.054, \varepsilon=$ 0.422 , partial $\eta^{2}=0.128, p=0.122$ ). The P3a amplitude evoked by $\mathrm{SC}$ was significantly higher than those evoked by OC and TC $(p<0.05$; Fig. 7 and Table 2). Similarly, for P3a latency there was no significant main effect or interaction for any factor.

\section{Discussion}

The present study showed that when the three deviant stimuli consisting of OC, SC and TC were presented 1) although some differences did not reach statistical significance for the telencephalon, the N1 amplitude evoked by TC was significantly greater than those evoked by $\mathrm{OC}$ and SC, while the N1 amplitude evoked by $\mathrm{OC}$ was significant greater than that by $\mathrm{SC} ; 2$ ) the $\mathrm{P} 2$ amplitudes evoked by $\mathrm{OC}$ and $\mathrm{SC}$ were significantly

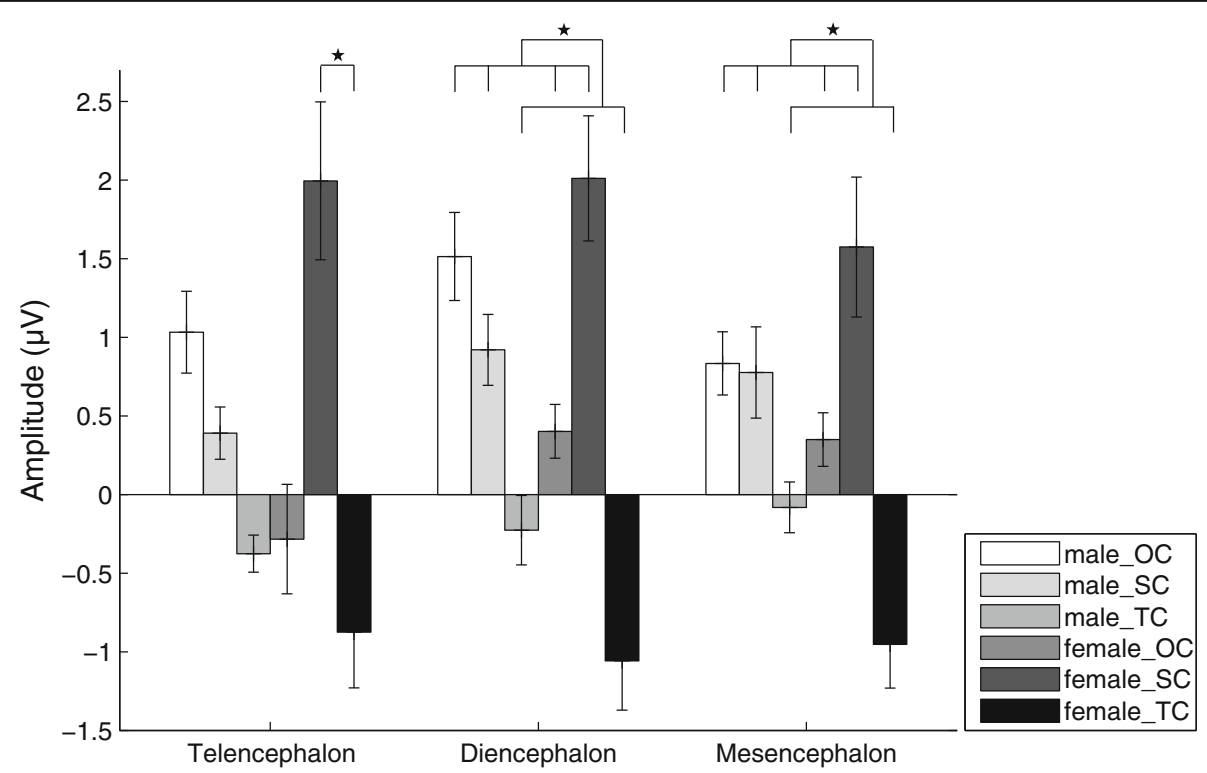

Fig. 6 Means and standard errors for P2 amplitudes during playbacks of the three deviant stimuli for the telencephalon, diencephalon and mesencephalon respectively. OC, the original call; SC, the version with each original note reversed (only spectral characteristics remained); TC, the version with white noise enveloped by the original note (only temporal characteristics remained) 


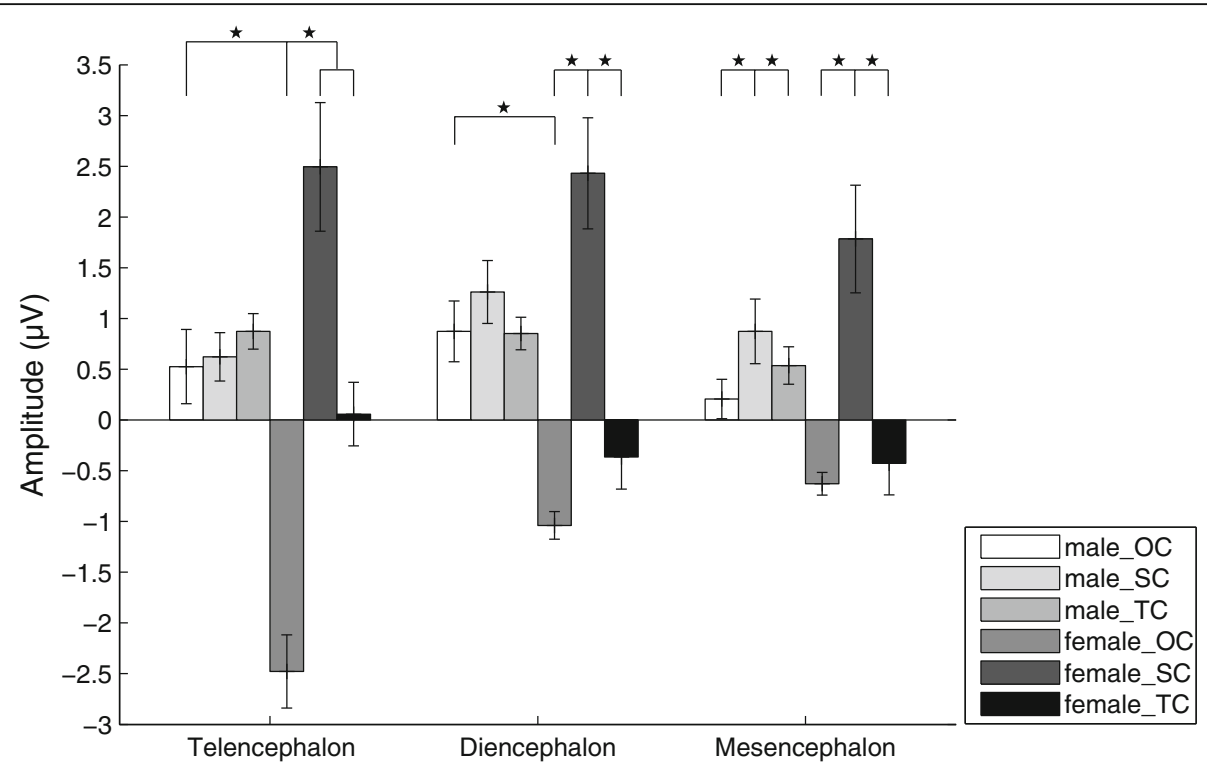

Fig. 7 Means and standard errors for P3a amplitudes during playbacks of the three deviant stimuli for the telencephalon, diencephalon and mesencephalon respectively. OC, the original call; SC, the version with each original note reversed (only spectral characteristics remained); TC, the version with white noise enveloped by the original note (only temporal characteristics remained)

greater than that by $\mathrm{TC}$ although the difference between $\mathrm{OC}$ and TC did not reach statistical significance for the telencephalon; 3) the P3a amplitudes evoked by SC and $\mathrm{TC}$ were significantly higher than by $\mathrm{OC}$ although the differences between TC and OC did not reach statistical significance for the diencephalon and mesencephalon; in addition, P3a amplitudes in the forebrain evoked by OC were significantly higher in males than in females. These results are consistent with the hypothesis that auditory processing of conspecific vocalization prefers to spectral features compared with temporal ones in the music frog. Moreover, the current results suggest that the neural processing for auditory perception is sexually dimorphic.

\section{Neural processing of conspecific vocalization prefers to spectral features}

Spectral and temporal processing refers to the transformations in how the spectral and temporal structures of sounds is represented in the central auditory system. In the present study, significant differences in N1 and P2 amplitudes were found exclusively between TC and other two stimuli in most conditions, although N1 amplitudes evoked by OC were also significantly higher than those by SC. In addition, the absolute values of difference of $\mathrm{N} 1$ or P2 amplitudes between $\mathrm{OC}$ and SC were smaller than those between OC and TC (Table 1), thus compared with $\mathrm{TC}$ the neural responses to $\mathrm{SC}$ were more similar to those for OC. Although SC shows reversed order of FM sweeps compared with OC, SC contains the same frequencies at the same relative amplitudes as OC. Accordingly, the present results were consistent with the prediction that more similar ERP components would be evoked by OC and SC if neural processing of conspecific vocalization depends on spectral features primarily. Compared with other deviant stimuli, higher N1 amplitude evoked by TC is consistent with the idea that the negative $\mathrm{N} 1$ waves can be affected by selective attention which enhances the perception of high-priority stimuli at the expense of other stimuli in the environment $[53,82]$. Animals usually pay attention to conspecific sounds with high salience and generally maintain alertness to absolute novelty of sounds (according to past auditory experience of the subject) which may be associated with danger [83-85], and that the stimuli with high emotional valence may capture attention [86, 87]. Accordingly, this strong selective pressure would likely result in a large "N1 effect of selective attention" [88]. Since more similar N1 was evoked by OC and SC, higher N1 amplitude evoked by TC would be more likely resulted from absolute novelty rather than conspecific salience involved in this sound. In addition, $\mathrm{N} 1$ is known to be sensitive to onset parameters [76] such as rise time with $\mathrm{N} 1$ peak amplitude reducing when stimulus rise time increases [89]. Consistent with this, the present results showed that the $\mathrm{N} 1$ amplitude evoked by $\mathrm{SC}$ with longest rise time was smallest.

The P2 component reflects the process of signal evaluation and classification, and is thought to be a connected with the memory processing and will compare the real-time perception input with the memory [54, 90, 91]. Moreover, its amplitude enhancement can result from prolonged training in mammals. Therefore P2 amplitude 
can be enhanced by familiarity or similarity between the target and current stimulus [54, 90-93], i.e. more familiar stimuli will evoke larger P2 waveforms [94]. Since humanlike auditory ERP components may indicate similar brain functions because of important conserved neuroanatomical features in vertebrate brain [66, 67], the present results showing $\mathrm{OC}$ and $\mathrm{SC}$ evoked higher P2 amplitude than TC did suggest SC compared with TC seemed to be more like conspecific vocalization. However, future research is required to verify it via behavioral experiments. In addition, the acoustic complexity can effect on the P2 amplitude significantly [95]. If this is the case, TC would be expected to evoke a relatively larger P2 amplitude because of its most complexity. However, OC and SC actually evoked a larger P2 amplitudes compared with TC, so it is likely that these results for P2 did not occur because of the presumed effects of complexity, thus implying that the similar spectral characteristics of sounds are the key factors for P2 profiles in the music frogs. Thus, neural processing of conspecific vocalization may prefer to spectral features in this species. This speculation has been verified partly by discriminant function analysis of calls in the music frog [38], which show the spectral features may provide more sufficient information for individual recognition compared with the temporal ones.

At the individual level, some kinds of acoustic properties of advertisement calls typically show very little variation (static properties) and others are highly variable (dynamic properties) [96]. Variability in static properties is usually constrained within individual, therefore these properties are highly invariant from call to call within and between bouts of calling by an individual. Typically these properties include spectral features such as the fundamental frequency or dominant frequency or carrier frequency and fine-scale temporal properties such as the duration, rise-fall features and repetition rate of the short sounds (pulses) [96]. In contrast, anuran individuals readily alter gross-temporal properties of advertisement calls within and between calling bouts, such as the rate of calling, duration of calls or call-notes and rate of call-note production [97]. Since such signals may be more easily detected against the chorus background, females usually prefer calls with longer duration and higher rate. However, for an individual of the music frogs the spectral attributes of advertisement call remain relatively stable compared with the temporal ones [38, $41,98]$, suggesting the static properties in this species include spectral features primarily rather than temporal characteristics. Taken together, static variables, i.e. spectral features in the music frogs, are presumably more important for species discrimination and individual recognition, although dynamic variables like call rate and call duration are indicative of motivation or quality of the emitter [97] and may play an important role in female choice.

\section{Auditory perception on temporal and spectral features of calls exhibits sexual dimorphism}

Sexually dimorphic behaviors are widespread in vocal animals such as insects, birds and anurans [48, 65, 99105]. In general, females may be mute or exhibit a severely limited vocal repertoire while males are typically highly vocal and generally produce complex species-specific vocalizations to attract females for breeding, as well as to deter rivals [24, 106]. Moreover, males and females often react differently in response to conspecific calls, during which males are much more likely than females to respond to signals which vary from the species' norm [101]. These behavioral differences depend on neural systems that are sex-specific or common to males and females but potentially regulate a number of behaviors differently [107]. In other words, sex differences in auditory processing may reflect differences in the requirement for processing sex-specific aspects of vocal signals [97].

The present results show that the P3a amplitudes evoked by $\mathrm{OC}$ are significantly greater for males than females regardless of brain area, although the differences for the mesencephalon did not reach statistical significance (Fig. 7). P3a is usually evoked by the novel stimulus (relative novelty) with small proportion of occurrence [108]. Its amplitude is appears to be a reflection of automatic detection of a different stimulus or stimulus relative novelty, i.e. novel or more salient differences between standard and deviant stimuli produce larger P3a waves [60]. Furthermore, familiar sounds evoke smaller P3a compared with unfamiliar ones [61]. In this way, SC would be expected to evoke a relatively larger P3a amplitude because of sound familiarity for OC and almost identical spectral attributes between standard and TC.

Previous study showed that males are more permissive than females in their responses to signals [101]. Consistent with this idea, egr-1 expression in the auditory midbrain of male túngara frogs (Physalaemus pustulosus) increases in response to either conspecific or heterospecific calls but only increases in response to conspecific signals in females [103]. Similarly, a previous study of the auditory midbrain in large odorous frogs (Odorrana graminea) showed that the most sensitive frequency range in males is almost double bandwidth of females [109]. These results imply that in at least some species males may process more acoustic information than females when they are under the same auditory scene. Thus, more relatively novel or more salient differences between standard and deviant stimuli may be detected in males compared with females during acoustic signal 
perception. These sex differences are consistent with the fact that the cost of not responding to a potential sexual signal would be greater in males than females while the cost of responding inappropriately to sexual solicitation signals would be greater in females than males [110, 111]. Interestingly, the auditory brainstem response amplitude of male house sparrows (Passer domesticus), increases at a greater rate than that of females as the amplitude of the stimulus increases [16]. These findings, including the present results, suggest that sex differences in auditory processing occur but that the exact nature of these differences is both species specific and time specific, and that sexual dimorphism in auditory perception evolved in diverse vocal species.

The present results also show that the P3a amplitudes evoked by SC and TC in the telencephalon and diencephalon are greater than that by $\mathrm{OC}$ in females but not males. These results are generally consistent with other studies on P3a, showing less relative novelty or more familiarity in sounds elicit decreased P3a amplitude while more relative novelty or less familiarity in sounds elicit increased P3a amplitude [61] and with the idea that the forebrain may play an important role in auditory perception [65]. No specific sensory areas in the anuran telencephalon appear homologous to the auditory areas of the amniote telencephalon insofar as the anuran pallium is not parcellated into discrete functional areas, although widespread connections linking forebrain neurons to motor and/or endocrine systems and limbic structures exist [112]. Thus the sex differences in P3a amplitude in the telencephalon observed in the present study may reflect the differential effects in males and females of selection pressures associated with identifying male conspecific call differences and in decision making associated with responding to male calls. Consistent with this, simple stimuli such as clicks generally fail to excite cells in the frog telencephalon [113]; in contrast, complex signals similar to natural calls can induce large neuronal responses in the striatum and medial pallium. Lesions of the striatum, superficial and deep thalamic structures may disrupt vocal recognition [114], indicating that telencephalic and thalamic areas play important roles in call recognition. Consequently, more telencephalic resources appear to be involved in higher level cognition functions such as mate choice in females than in males during the breeding season.

\section{Conclusion}

Taken together, we found evidence that more similar ERP components were evoked by the original call and its transformation version with most spectral features preserved, compared with the other version with temporal characteristics preserved. Moreover, the P3a amplitudes in the forebrain evoked by the original call were significantly higher in males than in females. These results suggest neural processing for conspecific vocalization may prefer to the spectral features of species-specific call in the music frogs, prompting speculation that the spectral features may play more important roles in auditory object perception or vocal communication in this species. In addition, the neural processing for auditory perception is sexually dimorphic.

\section{Acknowledgements}

We would like to thank Jianguo Cui for his suggestions on experimental designs. We also thank the two anonymous reviewers for helpful comments on the manuscript.

\section{Funding}

This work was supported by the grants from the National Key Research and Development Program of China (No. 2016YFC0500104) and the National Natural Science Foundation of China (No. 31672305 and No. 31372217 to G.F., No. 31572275 to Y.T.)

\section{Availability of data and materials}

The datasets used and/or analyzed during the current study are available from the corresponding author on reasonable request.

\section{Authors' contributions}

GF and $Y T$ conceived the project. $Y F, X Y$ and GF designed the experiment. $X Y, J Y, J S$ and DS collected the data. YF and $X Y$ analyzed the dataset and wrote the original draft. Funding Acquisition and Resources: $Y T$ and GF. All authors contributed critically in preparing the manuscript and gave final approval for publication.

\section{Ethics approval}

All experimental procedures were approved by the Animal Care and Use Committee of Chengdu Institute of Biology. All surgeries were performed with tricaine methanesulfonate (MS-222) anesthesia and all efforts were made to minimize discomfort.

\section{Consent for publication}

Not applicable.

\section{Competing interests}

The authors declare that they have no competing interests.

\section{Publisher's Note}

Springer Nature remains neutral with regard to jurisdictional claims in published maps and institutional affiliations.

\section{Author details}

'Department of Herpetology, Chengdu Institute of Biology, Chinese Academy of Sciences, No.9 Section 4, Renmin Nan Road, Chengdu, Sichuan 610041, People's Republic of China. 'University of Chinese Academy of Sciences, 19A Yuquan Road, Beijing, People's Republic of China.

Received: 6 November 2018 Accepted: 22 April 2019

Published online: 10 May 2019

References

1. $\mathrm{Xu}$ J, Gooler DM, Feng AS. Effects of sound direction on the processing of amplitude-modulated signals in the frog inferior colliculus. J Comp Physiol A. 1996;178:435-45.

2. Naguib M, Janik V, Clayton N, Zuberbuhler K. Vocal communication in birds and mammals. London: Academic Press; 2009.

3. Ronacher B. Processing of species-specific signals in the auditory pathway of grasshoppers. In: Berthold H, editor. Insect hearing and acoustic communication. New York: Springer; 2014. p. 185-204.

4. Feng AS, Schul J. Sound processing in real-world environments. In: Narins PM, Feng AS, Fay RR, Popper AN, editors. Hearing and sound communication in amphibians. New York: Springer; 2007. p. 323-50. 
5. Schwartz JJ. The importance of spectral and temporal properties in species and call recognition in a neotropical treefrog with a complex vocal repertoire. Anim Behav. 1987;35:340-7.

6. Capranica RR, Moffat AJ. Neurobehavioral correlates of sound communication in anurans. In: Ewert JP, editor. Advances in vertebrate neuroethology. New York: Springer; 1983. p. 701-30.

7. Riebel K. Song and female mate choice in zebra finches: a review. Adv Stud Behav. 2009;40:197-238.

8. Bee MA, Signaler MCT, Psychology R. In: Bee MA, Miller CT, editors Psychological mechanisms in animal communication. Gewerbestrasse: Springer; 2016. p. 1-16.

9. Aubin T, Jouventin P. How to vocally identify kin in a crowd: the penguin model. Adv Stud Behav. 2002;31:243-78.

10. Brumm H, Slabbekoorn H. Acoustic communication in noise. Adv Stud Behav. 2005:35:151-209.

11. Nelson DA, Marler P. The perception of birdsong and an ecological concept of signal space. In: Stebbins WC, Berkley MA, editors. Wiley series in neuroscience. Oxford, England: Wiley; 1990. p. 443-78.

12. Williams H, Cynx J, Nottebohm F. Timbre control in zebra finch (Taeniopygia guttata) song syllables. J Comp Psychol. 1989;103:366-80.

13. Fang K, Zhang BW, Brauth SE, Tang YZ, Fang GZ. The first call note of the Anhui tree frog (Rhacophorus zhoukaiya) is acoustically suited for enabling individual recognition. Bioacoustics. 2019;28:155-76.

14. Marquez R, Delariva I, Bosch J. Advertisement calls of Bolivian Leptodactylidae (Amphibia, Anura). J Zool. 1995;237:313-36.

15. Shen JX, Feng AS, Xu ZM, Yu ZL, Arch VS, Yu XJ, Narins PM. Ultrasonic frogs show hyperacute phonotaxis to female courtship calls. Nature. 2008:453:914-6.

16. Henry KS, Gall MD, Vélez A, Lucas JR. Avian auditory processing at four different scales: variation among species, seasons, sexes, and individuals. In: Bee MA, Miller CT, editors. Psychological mechanisms in animal communication. Gewerbestrasse: Springer; 2016. p. 17-55.

17. Beckers GJ, Ten Cate C. Perceptual relevance of species-specific differences in acoustic signal structure in Streptopelia doves. Anim Behav. 2001;62:511-8.

18. Joris P, Schreiner C, Rees A. Neural processing of amplitude-modulated sounds. Physiol Rev. 2004;84:541-77.

19. Johnson $\mathrm{DH}$. The relationship between spike rate and synchrony in responses of auditory-nerve fibers to single tones. J Acoust Soc Am. 1980;68:1115-22.

20. Henry KS, Gall MD, Bidelman GM, Lucas JR. Songbirds tradeoff auditory frequency resolution and temporal resolution. J Comp Physiol A. 2011;197:351-9.

21. Bizley JK, Cohen YE. The what, where and how of auditory-object perception. Nat Rev Neurosci. 2013;14:693-707.

22. Griffiths TD, Warren JD. What is an auditory object? Nat Rev Neurosci. 2004; 5:887-92.

23. Bee MA. Sound source perception in anuran amphibians. Curr Opin Neurobiol. 2012;22:301-10.

24. Arch VS, Narins PM. Sexual hearing: the influence of sex hormones on acoustic communication in frogs. Hear Res. 2009;252:15-20.

25. Kelley DB. Vocal communication in frogs. Curr Opin Neurobiol. 2004;14:751-7.

26. Tobias ML, Corke A, Korsh J, Yin D, Kelley DB. Vocal competition in male Xenopus laevis frogs. Behav Ecol Sociobiol. 2010;64:1791-803.

27. Gerhardt HC. Acoustic communication in two groups of closely related treefrogs. Adv Stud Behav. 2001;30:99-167.

28. Drewry GE, Rand AS. Characteristics of an acoustic aommunity: Puerto Rican frogs of the genus Eleutherodactylus. Copeia. 1983;1983:941-53.

29. Bee MA, Gerhardt HC. Neighbour-stranger discrimination by territorial male bullfrogs (Rana catesbeiana): I. acoustic basis. Anim Behav. 2001;62:1129-40.

30. Gerhardt HC. Mating call recognition in the barking treefrog (Hyla gratiosa): responses to synthetic calls and comparisons with the green treefrog (Hyla cinerea). J Comp Physiol A. 1981;144:17-25.

31. Murphy CG, Gerhardt HC. Mating preference functions of individual female barking treefrogs, Hyla gratiosa, for two properties of male advertisement calls. Evolution. 2000;54:660-9.

32. Allan SE, Simmons AM. Temporal features mediating call recognition in the green treefrog, Hyla cinerea: amplitude modulation. Anim Behav. 1994;47:1073-86.

33. Ghazanfar AA, Smith-Rohrberg D, Hauser MD. The role of temporal cues in rhesus monkey vocal recognition: orienting asymmetries to reversed calls. Brain Behav Evol. 2001;58:163-72.

34. Gerhardt HC. Mating call recognition in the green treefrog (Hyla cinerea): the significance of some fine-temporal properties. J Exp Biol. 1978;74:59-73.

35. Vignal C, Kelley DB. Significance of temporal and spectral acoustic cues for sexual recognition in Xenopus laevis. Proc R Soc B Biol Sci. 2007;274:479.
36. Mudry KM, Constantine-Paton M, Capranica RR. Auditory sensitivity of the diencephalon of the leopard frog Rana p. pipiens. J Comp Physiol A. 1977 114:1-13.

37. Mangiamele LA, Burmeister SS. Acoustically evoked immediate early gene expression in the pallium of female túngara frogs. Brain Behav Evol. 2008;72:239-50.

38. Chen Q, Cui JG, Fang GZ, Brauth SE, Tang YZ. Acoustic analysis of the advertisement calls of the music frog, Babina daunchina. J Herpetol. 2011;45:406-16.

39. Cui JG, Wang YS, Brauth SE, Tang YZ. A novel female call incites malefemale interaction and male-male competition in the Emei music frog, Babina daunchina. Anim Behav. 2010;80:181-7.

40. Cui JG, Tang YZ, Narins PM. Real estate ads in Emei music frog vocalizations: female preference for calls emanating from burrows. Biol Lett. 2012;8:337-40.

41. Fang GZ, Jiang F, Yang $P$, Cui JG, Brauth SE, Tang YZ. Male vocal competition is dynamic and strongly affected by social contexts in music frogs. Anim Cogn. 2014;17:483-94.

42. Greenfield MD, Rand AS. Frogs have rules: selective attention algorithms regulate chorusing in Physalaemus pustulosus (Leptodactylidae). Ethology. 2000;106:331-47.

43. Krauzlis RJ, Bogadhi AR, Herman JP, Bollimunta A. Selective attention without a neocortex. Cortex. 2018;102:161-75.

44. Wells KD, Schwartz JJ. The behavioral ecology of anuran communication. In: Narins PM, Feng AS, Fay RR, Popper AN, editors. Hearing and sound communication in amphibians. New York: Springer; 2007. p. 44-86.

45. Fang GZ, Yang P, Xue F, Cui JG, Brauth SE, Tang YZ. Sound classification and call discrimination are decoded in order as revealed by event-related potential components in frogs. Brain Behav Evol. 2015;86:232-45.

46. Yue $X Z$, Fan $Y Z$, Xue F, Brauth SE, Tang YZ, Fang GZ. The first call note plays a crucial role in frog vocal communication. Sci Rep UK. 2017;7:10128.

47. Xue F, Yue XZ, Fan YZ, Cui JG, Brauth SE, Tang YZ, Fang GZ. Auditory neural networks involved in attention modulation prefer biologically significant sounds and exhibit sexual dimorphism in anurans. J Exp Biol. 2018;221(5). https://doi.org/10.1242/jeb.167775.

48. Yang P, Xue F, Cui JG, Brauth SE, Tang YZ, Fang GZ. Auditory sensitivity exhibits sexual dimorphism and seasonal plasticity in music frogs. J Comp Physiol A. 2018;204:1029-44.

49. Fang GZ, Xue F, Yang P, Cui JG, Brauth SE, Tang YZ. Right ear advantage for vocal communication in frogs results from both structural asymmetry and attention modulation. Behav Brain Res. 2014;266:77-84.

50. Xue F, Fang GZ, Yang P, Zhao EM, Brauth SE, Tang YZ. The biological significance of acoustic stimuli determines ear preference in the music frog. J Exp Biol. 2015;218:740-7.

51. Kandel ER, Schwartz JH, Jessell TM, Siegelbaum SA, Hudspeth AJ. Principles of neural science. 5th ed. New York: McGraw-Hill; 2013.

52. Luck SJ. An introduction to the event-related potential technique. Cambridge: MIT Press; 2005.

53. Näätänen $\mathrm{R}$, Picton $\mathrm{T}$. The $\mathrm{N} 1$ wave of the human electric and magnetic response to sound: a review and an analysis of the component structure. Psychophysiology. 1987;24:375-425

54. Shahin A, Roberts LE, Pantev C, Trainor LJ, Ross B. Modulation of P2 auditory-evoked responses by the spectral complexity of musical sounds. Neuroreport. 2005;16:1781-5.

55. Tremblay K, Kraus N, McGee T, Ponton C, Otis B. Central auditory plasticity: changes in the N1-P2 complex after speech-sound training. Ear Hear. 2001;22:79-90.

56. Tremblay KL, Kraus N. Auditory training induces asymmetrical changes in cortical neural activity. J Speech Lang Hear Res. 2002;45:564-72.

57. Luck SJ, Kappenman ES. The Oxford handbook of event-related potential components. New York: Oxford university press; 2011.

58. Hall JW III. eHandbook of auditory evoked responses: principles, procedures \& protocols. Pretoria: Pearson; 2015

59. Friedman D, Cycowicz YM, Gaeta H. The novelty P3: an event-related brain potential (ERP) sign of the brain's evaluation of novelty. Neurosci Biobehav Rev. 2001;25:355-73.

60. Wronka E, Kaiser J, Coenen AML. Neural generators of the auditory evoked potential components P3a and P3b. Acta Neurobiol Exp (Warsz). 2012;72:51-64.

61. Cycowicz YM, Friedman D. Effect of sound familiarity on the event-related potentials elicited by novel environmental sounds. Brain Cogn. 1998;36:30-51.

62. Arthur DL, Starr A. Task-relevant late positive component of the auditory event related potential in monkeys resembles P300 in humans. Science. 1984;223:186-8.

63. Ehlers CL, Kaneko WM, Robledo P, Lopez AL. Long-latency event-related potentials in rats: effects of task and stimulus parameters. Neuroscience. 1994;62:759-69. 
64. Woods DL, Ridgway SH, Bullock TH. Middle-and long-latency auditory event-related potentials in dolphins. In. Schusterman JR, Thomas JA, wood FG, editors. Dolphin cognition and behavior: a comparative perspective. London: Lawrence Erlbaum Associates; 1986. p. 61-77.

65. Fan YZ, Yue XZ, Xue F, Cui JG, Brauth SE, Tang YZ, Fang GZ. Auditory perception exhibits sexual dimorphism and left telencephalic dominance in Xenopus laevis. Biol Open. 2018;7(12). https://doi.org/10.1242/bio.035956.

66. Finlay BL, Darlington RB, Nicastro N. Developmental structure in brain evolution. Behav Brain Sci. 2001;24:298-308.

67. Northcutt RG. Understanding vertebrate brain evolution. Integr Comp Biol. 2002:42:743-56.

68. Fang GZ, Chen Q, Cui JG, Tang YZ. Electroencephalogram bands modulated by vigilance states in an anuran species: a factor analytic approach. J Comp Physiol A. 2012;198:119-27.

69. Fang GZ, Yang P, Cui JG, Yao DZ, Brauth SE, Tang YZ. Mating signals indicating sexual receptiveness induce unique spatio-temporal EEG theta patterns in an anuran species. PLoS One. 2012;7:e52364.

70. Lalonde-Robert V, Desgent S, Duss S, Vachon P. Electroencephalographic and physiologic changes after tricaine methanesulfonate immersion of African clawed frogs (Xenopus laevis). J Am Assoc Lab Anim. 2012;51:622-7.

71. Fan YZ, Yue XZ, Xue F, Brauth SE, Tang YZ, Fang GZ. The right thalamus may play an important role in anesthesia-awakening regulation in frogs. PeerJ. 2018;6:e4516.

72. Wilczynski W. Brainstem auditory pathways in anuran amphibians. In: Fritzsch B, Ryan MJ, Wilczynski W, Hetherington T, Walkowiak W, editors. The evolution of the amphibian auditory system. New York: Wiley; 1988. p. 209-31.

73. Gonsalvez CJ, Polich J. P300 amplitude is determined by target-to-target interval. Psychophysiology. 2002;39:388-96.

74. Oconnor TA, Starr A. Intracranial potentials correlated with an event-related potential, P300, in the cat. Brain Res. 1985:339:27-38.

75. Deveney CM, Pizzagalli D. The cognitive consequences of emotion regulation: an ERP investigation. Psychophysiology. 2008:45:435-44.

76. Biermann S, Heil P. Parallels between timing of onset responses of single neurons in cat and of evoked magnetic fields in human auditory cortex. J Neurophysiol. 2000;84:2426-39.

77. Ostroff JM, McDonald KL, Schneider BA, Alain C. Aging and the processing of sound duration in human auditory cortex. Hear Res. 2003;181:1-7.

78. Yago E, Escera C, Alho K, Giard M-H, Serra-Grabulosa JM. Spatiotemporal dynamics of the auditory novelty-P3 event-related brain potential. Cogn Brain Res. 2003;16:383-90.

79. McDonald JJ, Teder-Sälejärvi WA, Di Russo F, Hillyard SA. Neural basis of auditoryinduced shifts in visual time-order perception. Nat Neurosci. 2005:8:1197.

80. Shu H. Factorial experimental design in psychology and education (in (Chinese). Beijing: Beijing Normal University Press; 2008.

81. Cohen J. A power primer. Psychol Bull. 1992;112:155-9.

82. Woldorff MG, Gallen CC, Hampson SA, Hillyard SA, Pantev C, Sobel D, Bloom FE. Modulation of early sensory processing in human auditory cortex during auditory selective attention. Proc Natl Acad Sci U S A. 1993;90:8722-6.

83. Haff T, Magrath RD. Vulnerable but not helpless: nestlings are fine-tuned to cues of approaching danger. Anim Behav. 2010;79:487-96.

84. Darrow PA, Shivik JA. Bold, shy, and persistent: variable coyote response to light and sound stimuli. Appl Anim Behav Sci. 2009;116:82-7.

85. Hemmi JM, Merkle T. High stimulus specificity characterizes anti-predator habituation under natural conditions. Proc Biol Sci. 2009;276:4381-8.

86. Anderson AK, Phelps EA. Lesions of the human amygdala impair enhanced perception of emotionally salient events. Nature. 2001;411:305-9.

87. Most SB, Wang L. Dissociating spatial attention and awareness in emotioninduced blindness. Psychol Sci. 2011;22:300-5.

88. Hillyard SA, Hink RF, Schwent VL, Picton TW. Electrical signs of selective attention in the human brain. Science. 1973;182:177-80.

89. Hyde M. The N1 response and its applications. Audiol Neurootol. 1997;2:281-307.

90. Bosnyak DJ, Eaton RA, Roberts LE. Distributed auditory cortical representations are modified when non-musicians are trained at pitch discrimination with $40 \mathrm{~Hz}$ amplitude modulated tones. Cereb Cortex. 2004 14:1088-99

91. Tremblay KL, Inoue K, McClannahan K, Ross B. Repeated stimulus exposure alters the way sound is encoded in the human brain. PLoS One. 2010;5: e10283.

92. Potts GF, Dien J, Hartry-Speiser AL, McDougal LM, Tucker DM. Dense sensor array topography of the event-related potential to task-relevant auditory stimuli. Electroencephalogr Clin Neurophysiol. 1998;106:444-56.
93. Reinke KS, He Y, Wang C, Alain C. Perceptual learning modulates sensory evoked response during vowel segregation. Cogn Brain Res. 2003;17:781-91.

94. Freunberger R, Klimesch W, Doppelmayr M, Höller Y. Visual P2 component is related to theta phase-locking. Neurosci Lett. 2007;426:181-6.

95. Shahin AJ, Roberts LE, Miller LM, McDonald KL, Alain C. Sensitivity of EEG and MEG to the $\mathrm{N} 1$ and $\mathrm{P} 2$ auditory evoked responses modulated by spectral complexity of sounds. Brain Topogr. 2007;20:55-61.

96. Gerhardt HC, Bee MA. Recognition and localization of acoustic signals. In: Narins PM, Feng AS, Fay RR, Popper AN, editors. Hearing and sound communication in amphibians. New York: Springer; 2007. p. 113-46.

97. Gerhardt HC, Huber F. Acoustic communication in insects and anurans: common problems and diverse solutions. Chicago: University of Chicago Press; 2002.

98. Jiang F, Fang GZ, Xue F, Cui JG, Brauth SE, Tang YZ. Male music frogs compete vocally on the basis of temporal sequence rather than spatial cues of rival calls. Asian Herpetol Res. 2015;6:305-16.

99. Yang P, Fang GZ, Xue F, Cui JG, Brauth SE, Tang YZ. Electroencephalographic signals synchronize with behaviors and are sexually dimorphic during the light-dark cycle in reproductive frogs. J Comp Physiol A. 2014;200:117-27.

100. Liu YS, Fan YZ, Xue F, Yue XZ, Brauth SE, Tang YZ, Fang GZ. Changes in electroencephalogram approximate entropy reflect auditory processing and functional complexity in frogs. Asian Herpetol Res. 2016;7:180-90.

101. Bernal XE, Rand AS, Ryan MJ. Sex differences in response to nonconspecific advertisement calls: receiver permissiveness in male and female túngara frogs. Anim Behav. 2007;73:955-64

102. Bernal XE, Stanley Rand A, Ryan MJ. Sexual differences in the behavioral response of túngara frogs, Physalaemus pustulosus, to cues associated with increased predation risk. Ethology. 2007;113:755-63.

103. Hoke KL, Ryan MJ, Wilczynski W. Candidate neural locus for sex differences in reproductive decisions. Biol Lett. 2008:4:518-21.

104. Gobes SM, ter Haar SM, Vignal C, Vergne AL, Mathevon N, Bolhuis JJ. Differential responsiveness in brain and behavior to sexually dimorphic long calls in male and female zebra finches. J Comp Neurol. 2009;516:312-20.

105. Xue F, Fang GZ, Yue XZ, Zhao EM, Brauth SE, Tang YZ. A lateralized functional auditory network is involved in anuran sexual selection. J Biosci. 2016;41:713-26.

106. McClelland BE, Wilczynski W, Rand AS. Sexual dimorphism and species differences in the neurophysiology and morphology of the acoustic communication system of two neotropical hylids. J Comp Physiol A. 1997; 180:451-62.

107. Hoke KL, Ryan MJ, Wilczynski W. Sexually dimorphic sensory gating drives behavioral differences in túngara frogs. J Exp Biol. 2010;213:3463-72.

108. van Dinteren $R$, Arns M, Jongsma ML, Kessels RP. P300 development across the lifespan: a systematic review and meta-analysis. PLoS One. 2014;9: e87347.

109. Liu WR, Shen JX, Zhang YJ, Xu ZM, Qi Z, Xue MQ. Auditory sexual difference in the large odorous frog Odorrana graminea. J Comp Physiol A. 2014;200: 311-6.

110. Searcy WA, Brenowitz EA. Sexual differences in species recognition of avian song. Nature. 1988;332:152

111. Wiley RH. Signal detection and animal communication. Adv Stud Behav. 2006:36:217-47.

112. Wilczynski W, Endepols $\mathrm{H}$. Central auditory pathways in anuran amphibians: the anatomical basis of hearing and sound communication. In: Narins PM, Feng AS, Fay RR, Popper AN, editors. Hearing and sound communication in amphibians. New York: Springer; 2007. p. 221-49.

113. Wilczynski W, Capranica RR. The auditory system of anuran amphibians. Prog Neurobiol. 1984;22:1-38.

114. Endepols H, Feng AS, Gerhardt HC, Schul J, Walkowiak W. Roles of the auditory midbrain and thalamus in selective phonotaxis in female gray treefrogs (Hyla versicolor). Behav Brain Res. 2003;145:63-77. 